\title{
Battery Monitoring System using Microcontroller
}

\author{
S. N. Patil \\ Asst.Prof., Electrical Engg. Dept., \\ TSSM's Padmabhooshan \\ Vasantdada \\ Patil Institute of Technology, Pune, Patil Institute of Technology, Pune, \\ India \\ Sangmeshwar S. Kendre \\ Lecturer, E\&TC Dept., \\ TSSM's Padmabhooshan \\ Vasantdada \\ India
}

\author{
Dr. R. C. Prasad \\ Professor, Electrical Engg. \\ Dept. \\ College of Military \\ Engineering, Pune, India
}

\begin{abstract}
Battery management system (BMS) forms a crucial system component in various applications like electric vehicles (EV), hybrid electric vehicles (HEV), uninterrupted power supplies (UPS), telecommunications and so on. The accuracy of these systems has always been a point of discussion as they generally give an error of maximum $10 \%$ considering all the parameters together. In this paper a system is presented which is developed using low cost microcontrollers for measurement of electrolyte temperature, electrolyte level and no. of backup hours parameters of lead-acid batteries. Since the batteries, which would be used in the hybrid electric vehicle (HEV), are lead-acid batteries, they will be the focus of this project. While the present prototype system accounts only for measuring backup hours of a car in a stationary as well as in a running mode. With the help of this, we are able to know the battery life span and its efficiency. Data backup is also provided to save the all records of battery.
\end{abstract}

\section{General Terms}

Battery Management System, Electric Vehicles et. al.

\section{Keywords}

Batteries; Battery monitoring System; Electric Vehicles; Battery Management System.

\section{INTRODUCTION}

With the increasing awareness of global warming around the world, the demand for clean fuel/energy is on the rise and as a result there is a continuous shift towards the electric vehicles (EVs) and hybrid electric vehicles (HEVs). Battery forms one of the most critical systems in any electric vehicle. Battery performance is influenced by factors such as depth of discharge (DOD), temperature and charging algorithm. EVs and HEVs use battery management system (BMS) to address the implementation of monitoring system parameters such as current, voltage and temperature. This paper attempts to provide a measurement of electrolyte temperature, electrolyte level and no. of backup hours parameters of lead-acid batteries.

\section{GENERAL DESCRIPTION OF THE DESIGNED EMBEDDED SYSTEM}

The designed system as shown in figure1.A is developed and it consists of total 5 slave modules connected to each
$12 \mathrm{~V}$ battery unit. This unit collect all data regarding battery and send it serially to master microcontroller.

Slave Unit: To each $12 \mathrm{~V}$ battery, there is a Slave unit is attached, which is used to measure surrounding temperature, actual voltage level of a battery. This unit is also indicates the low water level in a battery. This data is then sending serially to a Master unit. Block diagram of a slave unit is shown in figure 1.B..

Master Unit: This is a main part of this system. It is used to collect all data coming from Slave via RS232 cable. It also records this data with respect to time with the help of RTC and sends it to a LCD and PC. Hall Effect IC is used to measure current. The block diagram is shown in figure 1.C.

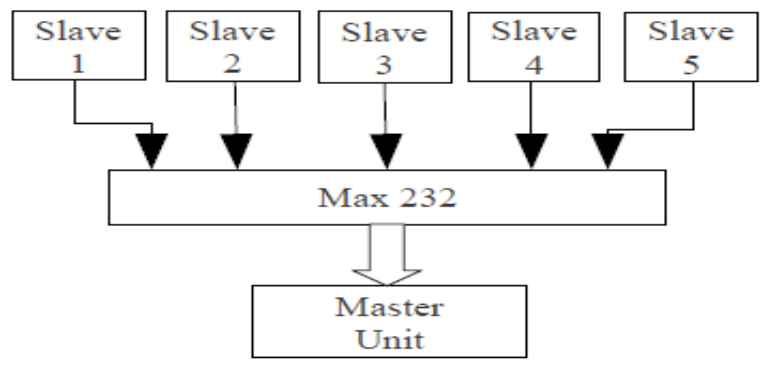

Fig.1.A. BMS

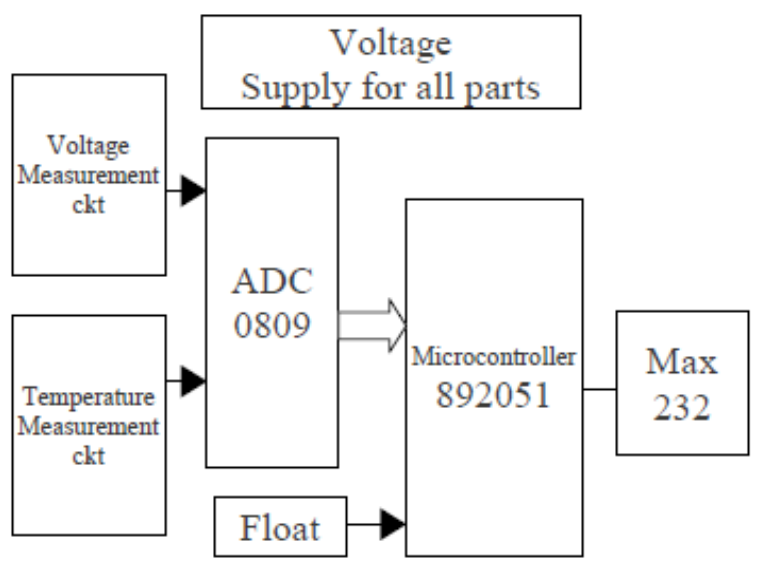

Fig.1.B. Block Diagram of Slave Unit 


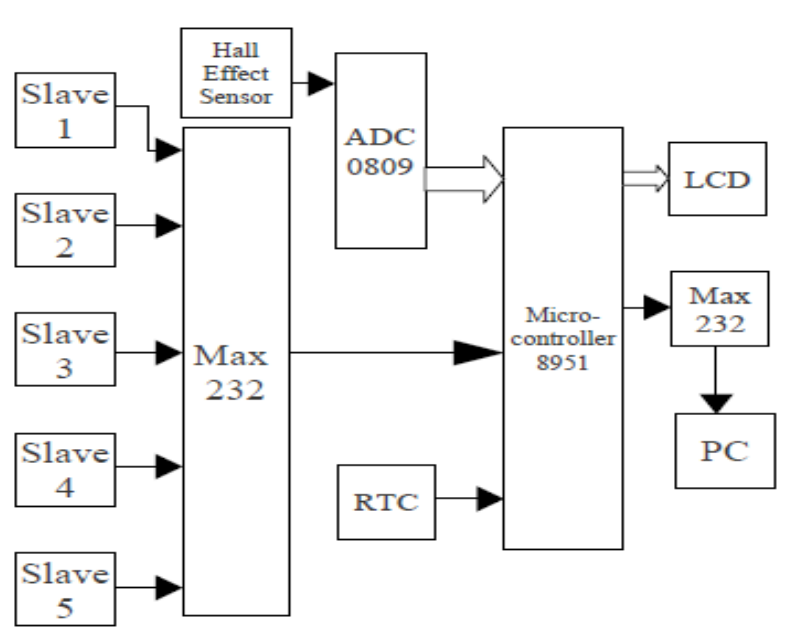

Voltage
Supply for all parts

Fig.1.C. Block Diagram of Master Unit

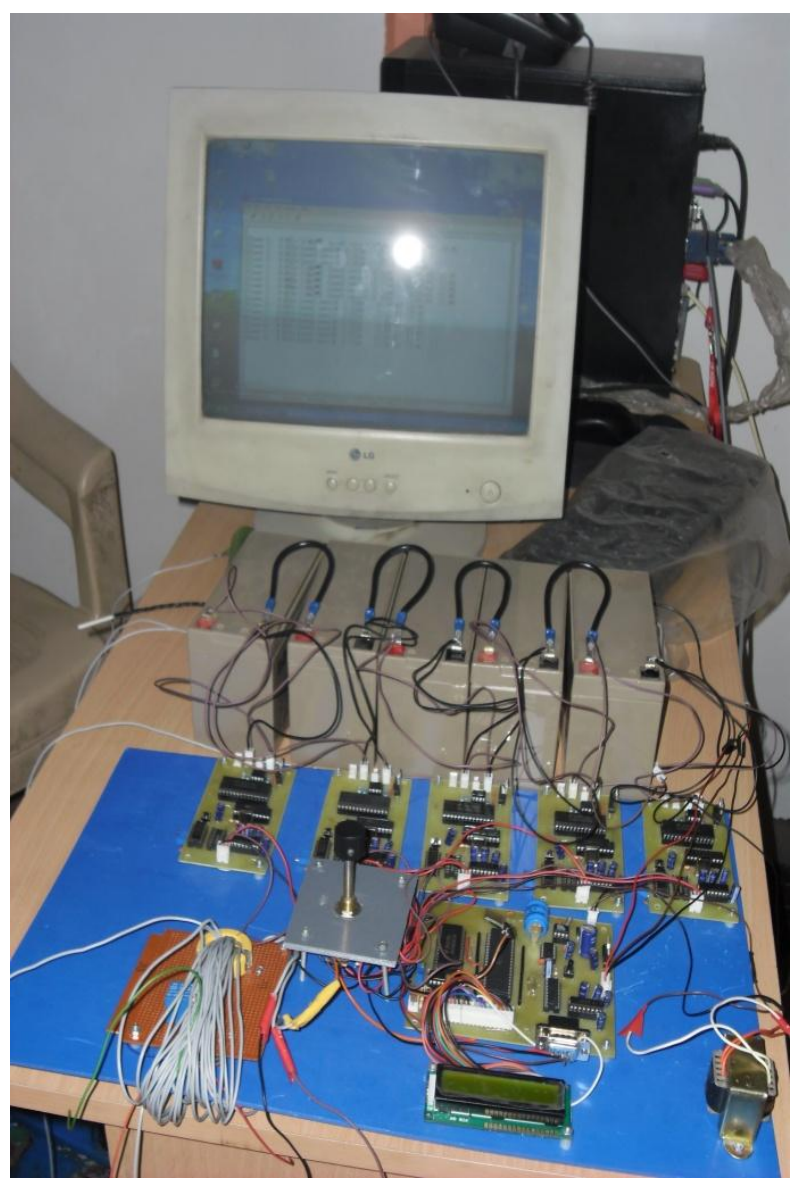

\section{ALGORITHM}

Slave Algorithm:

1. Start

2. Read analog voltage, temp.

3. Convert it into digital data.

4. If liquid level is low send emergency signal to master otherwise go at step 5 .

5. Send data serially to master.

6. Go at step 2 .

\section{Master Algorithm:}

1. Start

2. Show date and time on LCD.

3. Convert analog signal from current sensor into digital signal.

4. Store it in memory and display it on LCD in real time.

5. Display voltage, temperature, float level indication reading from 5 slaves one by one on LCD and store it in memory in real time.

6. Send data store in memory serially to PC.

7. Add voltage readings from 5 slaves and display it on LCD and store it in memory in real time.

8. Go at step 2 .

\section{DEVELOPING} AND RESULTS

\section{MIDE-51}

The microcontrollers program was simulated by using MIDE software as shown in Fig.2.

MIDE-51 is freeware Integrated Development Environment (IDE) for MCS-51 microcontroller. The full package already comes with:

Assembler: ASEM-51 by W.W.Heinz (v1.3) C compiler: SDCC: Small Device C Compiler (v2.5.4) Simulator : TS Controls 8051 Emulator v1.0 evaluation (Owner :

http://www.tscontrols.com was $\quad$ gone)
Simulator : JSIM-51 Simulator by Jens Altmann (v4.05)




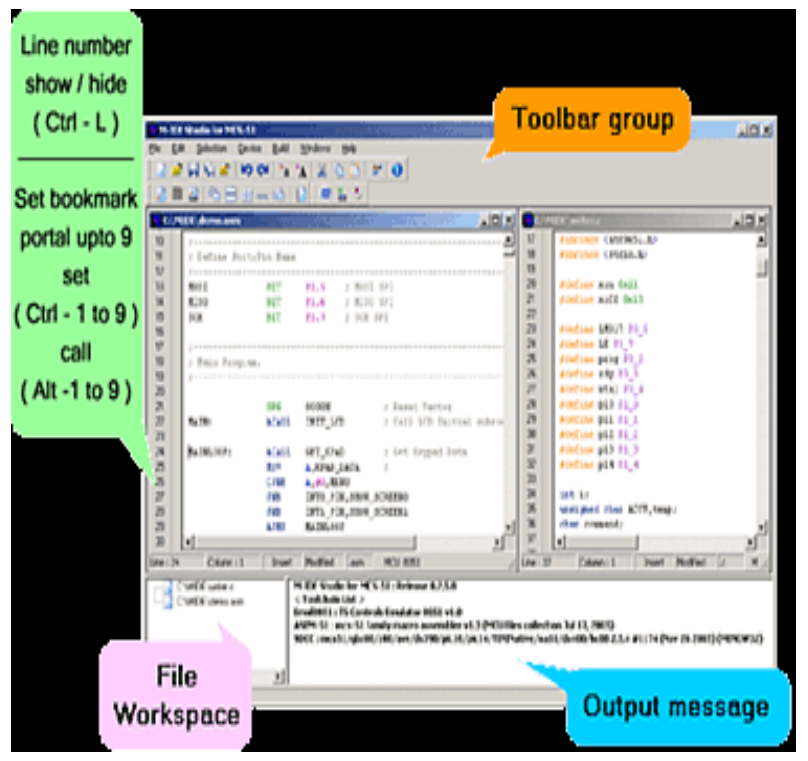

Fig.2. MIDE-51

\section{RESULTS}

\section{Hall Effect Sensor CS3500:}

The input given to this sensor is $5 \mathrm{~V}$. This sensor is placed in gap made in the Iron Dust core. Current carrying conductor is passed through the core, sensor shows the deflection. If the current is in positive direction, $\mathrm{o} / \mathrm{p} \mathrm{vlg}$ varies in between 2.5 to $5 \mathrm{~V}$. Otherwise, it varies in between 0 to $2.5 \mathrm{~V}$.

\section{Table.I. Test Hall effect sensor readings}

\begin{tabular}{|c|c|c|c|}
\hline Current(A) & Voltage(V) & Current(A) & Voltage(V) \\
\hline 0 & 2.445 & 16 & 2.509 \\
\hline 1 & 2.449 & 17 & 2.513 \\
\hline 2 & 2.453 & 18 & 2.517 \\
\hline 3 & 2.457 & 19 & 2.521 \\
\hline 4 & 2.461 & 20 & 2.525 \\
\hline 5 & 2.465 & 21 & 2.529 \\
\hline 6 & 2.469 & 22 & 2.533 \\
\hline 7 & 2.473 & 23 & 2.537 \\
\hline 8 & 2.477 & 24 & 2.541 \\
\hline 9 & 2.481 & 25 & 2.545 \\
\hline 10 & 2.485 & 26 & 2.549 \\
\hline 11 & 2.489 & 27 & 2.553 \\
\hline 12 & 2.493 & 28 & 2.557 \\
\hline 13 & 2.497 & 29 & 2.561 \\
\hline 14 & 2.501 & 30 & 2.565 \\
\hline 15 & 2.505 & & \\
\hline
\end{tabular}

The Graph of Current Vs O/P Voltage is shown in figure 3.

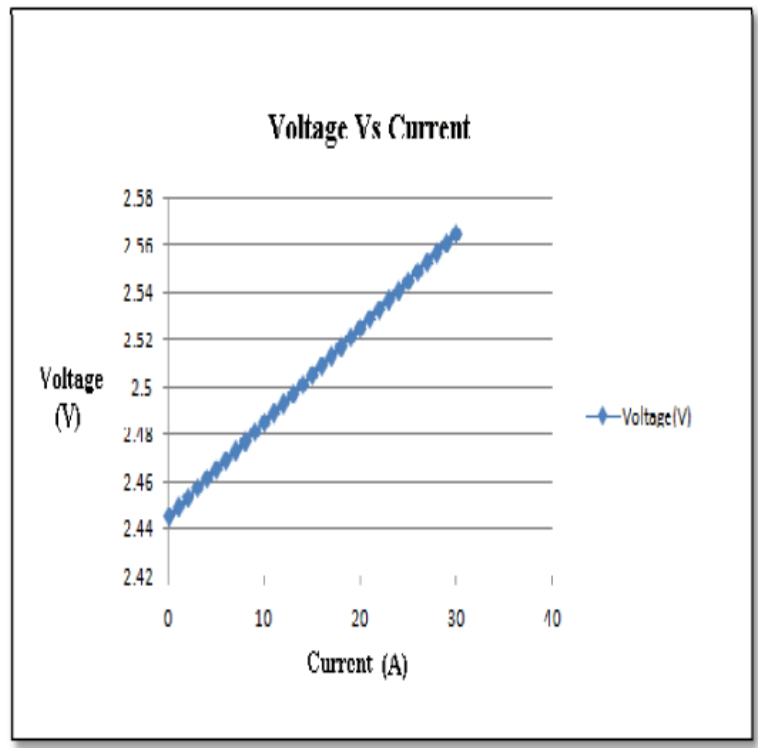

Fig.3. Graph of current Vs Voltage

\section{Discharge Characteristics of Battery:}

As battery used for longer time, battery voltage goes on reducing. This is called as discharge characteristics of battery. From this, we are able to know the backup given by battery. The following table 2 shows the discharge characteristics.

Table.II. Discharge Voltage

\begin{tabular}{|c|c|}
\hline Time(Min) & Voltage(V) \\
\hline 0 & 12.60 \\
\hline 10 & 12.42 \\
\hline 30 & 12.40 \\
\hline 60 & 12.34 \\
\hline 120 & 12.20 \\
\hline 180 & 12.06 \\
\hline 240 & 11.92 \\
\hline 300 & 11.72 \\
\hline 360 & 11.50 \\
\hline 420 & 11.18 \\
\hline 480 & 10.26 \\
\hline 540 & 10.20 \\
\hline
\end{tabular}


The following graph shows the discharge characteristics.

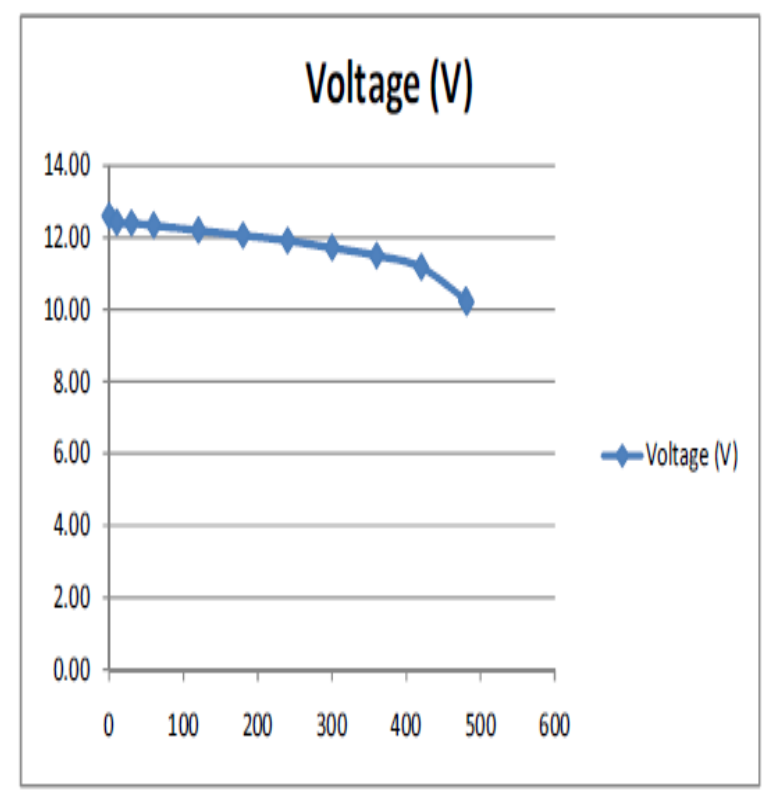

Fig.4. Graph of discharge

\section{Charging Characteristics of Battery:}

Charging characteristics shows the time required to charge battery at specific current. Following table 3 shows these characteristics.

Table.III. Charge Voltage

\begin{tabular}{|c|c|}
\hline Time(Hr) & Voltage(V) \\
\hline 0 & 11.80 \\
\hline 0 & 12.20 \\
\hline 0.5 & 12.80 \\
\hline 1 & 12.80 \\
\hline 1.5 & 13.00 \\
\hline 2 & 13.20 \\
\hline 2.5 & 13.20 \\
\hline 3 & 13.40 \\
\hline 3.5 & 13.60 \\
\hline 4 & 13.60 \\
\hline 5 & 14.00 \\
\hline 5.5 & 14.40 \\
\hline
\end{tabular}

Following graph shows the charging characteristics of

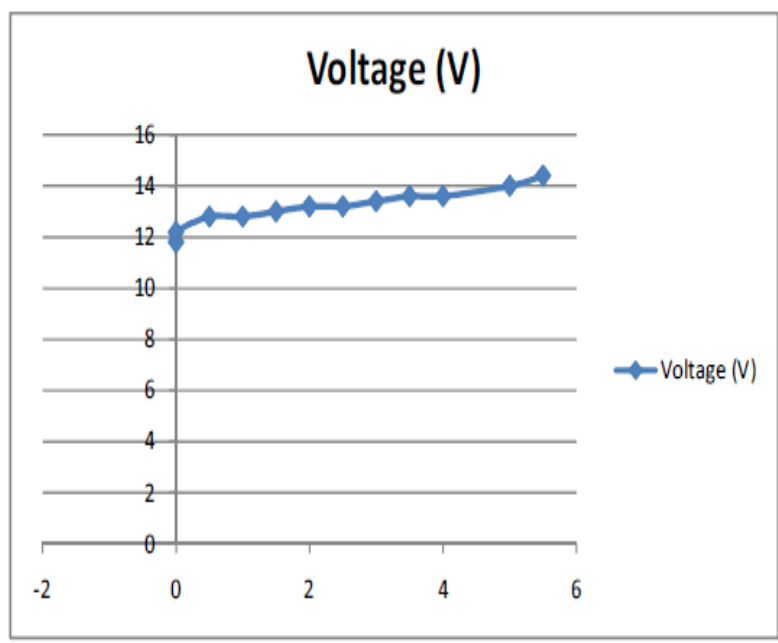

battery.

Fig.5. Graph of Charge

\section{CONCLUSION}

We have implemented "Battery Monitoring System" which is capable to measure electrolyte temperature, electrolyte level \& no. of backup hours given by battery of hybrid vehicle and can record all these parameters with respect to time and display it on LCD as well as on computer. We have tried our level best to make the project as good as possible. The system will help to ensure the efficient working of battery.

\section{REFERENCES}

[1] Y.-J. Lee, A. Khaligh, and A. Emadi, "Advanced integrated bidirectional AC/DC and DC/DC converter for plug-in hybrid electric vehicles," IEEE Trans. Veh. Technol., vol. 58, no. 8, pp. 3970-3980, Oct. 2009.

[2] H. V. Venkatasetty and Y. U. Jeong, "Recent advances in lithium-ion and lithium-polymer batteries," in Proc. 17th Annu. Battery Conf. Applications and Advances, Jan. 2002, pp. 173-178.

[3] Szumanowski and Y. Chang, "Battery management system based on battery nonlinear dynamics modeling," IEEE Trans. Veh. Technol., vol. 57, no. 3, pp. 1425-1432, May 2008.

[4] Affanni, A. Bellini, G. Franceschini, P. Guglielmi, and C. Tassoni, "Battery choice and management for newgeneration electric vehicles," IEEE Trans. Ind. Electron., vol. 52, no. 5, pp. 1343-1349, Oct. 2005.

[5] J. Bard and L. R. Faulkner, Electrochemical Methods: Fundamentals and Applications, 2nd ed. New York: Wiley, 2001. 